\title{
CONVERSAS COMPLICADAS COM OS CURRÍCULOS E OS CANTOS DOS ESTADOS-NAÇÃO
}

\author{
Maria Luiza Sussekind*
}

TEXTO ORIGINAL: BUTLER, Judith. SPIVAK, Gayatri Chakravorty. Quem canta o Estado-nação? Língua política, pertencimento. Tradução e Prefacio: Vanderlei J. Zacchi, Sandra Goulart Almeida. Brasília: Editora Universidade de Brasília, 2018.

Resumo:Trabalha a ideia de projeto de estado-nação, como promessa irrealizável, na perspectiva das políticas curriculares atuais no Brasil som suporte nas teorias de Pinar, Certeau e Boaventura de Sousa Santos.

Lançado em 2018 pela Editora UnB, Quem canta o Estado-nação? nos coloca diante de desafios epistemológicos, políticos e estéticos do pensamento contemporâneo. Para diletantes, pesquisadores e interessados nas discussões sobre currículos e políticas de controle e unificação curricular, orientadas por interesses empresariais e conservadores a obra desloca (e desmonta a naturalidade (p.13)) desse controle na direção de uma defesa da autonomia, criatividade e liberdade humana tensionada pelo questionamento político-epistemológico sobre o ato transgressivo como interpretação, linguagem e ocupação. Mesmo indevido, o outro existe e provoca existência, sendo assim presença, voz e resistência que abalroa a ideia de nós exigindo que se posicione como aniquilamento ou deslocamento (p. 34).

Desviantes, imigrantes-refugiados, professores, estudantes, ambientalistas, as mulheres lutando pelo aborto, movimentos LGBTQI+, e muitos outros subalternos (p.8), sabem que "ocupar a rua para protestar, exigir seus direitos e cantar o hino é um ato transgressivo" (p. 12). E o fazem como argumentam incisivamente os prefaciadores e tradutores Vanderlei J. Zacchi e Sandra Goulart Almeida, desafiando os pertencimentos jurídicos, linguísticos, étnicos, e subvertendo sua destituição pela transgressão, pela ocupação e pela tradução que desfiam a supressão da voz subalterna no estado em que estamos (p. 16). Vivendo a indecidibilidade do estado de exceção (fazendo uso de Agamben, p. 39, 40).

Nesse estado em que, mesmo quando acusados por anticomunistas de praticarem doutrinação ideológica, odiados por formarem crianças viadas (MOURA; SALES, 2018) e usarem o "kit-gay", advogamos que professores são praticantes nos cotidianos escolares que fazem múltiplos usos (CERTEAU, 1994; OLIVEIRA e

\footnotetext{
* Professora Adjunta da Escola de Educação e do PPGEdu da Universidade Federal do Estado do Rio de Janeiro/Unirio, pesquisadora Líder do GPPF/Grupo de Pesquisa Práticas Educativas e Formação de Professores, segunda secretaria nacional da ANPEd e pós-doutora em currículo pela UBC, Canadá 2013.
} 
SUSSEKIND, 2017) e ocupações transgressoras, que tanto preocupam as autoras do livro, não só nele. Nas línguas, nas universidades e escolas, nas ruas, nas ideias, cantando o hino nacional brasileiro em língua Terena (p. 5) somos transgressores, mesmo que involuntariamente, o que é uma promessa do irrealizável (p. 13). De acordo com os comentadores:

\begin{abstract}
A conversa crítica entre essas duas teóricas instigantes termina com um questionamento que nos leva de volta ao início, depois de uma viagem reflexiva por elas conduzida, com "a promessa do irrealizável", um movimento duplo que aponta para uma promessa e uma possibilidade talvez por meio de uma outra "linguagem"-, ao mesmo tempo em que nos mostra a dificuldade de lidar com temas tão espinhosos e controversos em um momento não menos complexo. (Idem)
\end{abstract}

Embora ambas autoras tragam uma experiência de cidadania americana, e sine qua non não americana, "tecem pertinentes considerações a respeito da situação, nos dias de hoje, dos sem-estado" (p. 7) diante de uma promessa de Estado-nação que trazendo Arendt, Spivak anuncia ser "defeituoso desde o princípio" (p. 70) e travam um diálogo que transcende áreas disciplinares (p. 8) tendo suas obras forte impacto no campo dos estudos em educação e do currículo, sobretudo na intersecção decolonial, das epistemologias do Sul e dos estudos que dialogam com as teorias pósestruturalistas. Nesse sentido, desviando dos tradutores (p.7, 8), penso que a contribuição entre Spivak e Butler desborda a teoria crítica multifrequentando conversas pós-críticas e oferecendo protagonismo à subalternidade e a performatividade como temas e, portanto, enfrentamento epistêmico. Se abordam "questões contemporâneas que afligem pessoas em todo o mundo, como as noções de cidadania, identidade, pertencimento e exílio" (p. 8) o fazem numa direção que venho tentando tratar como movimentos de deslocamento da teoria (SUSSEKIND, et al., 2013; SUSSEKIND, 2014b) frente à crise paradigmática do conhecimento científico na contemporaneidade sugestivamente embaladas pelos diálogos com os pensamentos de Giorgio Agamben, Arendt, Marx.

Como fez Pinar, ao denunciar o equívoco da educação pública americana e sua preocupação de se ter currículos eficientes em tornar imigrantes cidadãos (2008), no que concorda com Butler entendendo-os que são oferecidas apenas as condições de serem cidadãos "de segunda classe", por isso vulneráveis ao poder do estado e sem acesso a direitos, benefícios e prerrogativas da cidadania (p. 47, 48). Pinar vai tratar as 
questões de língua e identidade, inclusive dos professores - fluida e configurada de fora (2008), numa perspectiva que dialoga com Butler e com o que apresenta o livro resenhado em seu esforço de minar o Estado-nação, e sua opressão linguística, aniquilação histórica, exclusão política em seus hinos, cantos e interditos.

Entendo (2014b), a partir do argumento de Santos (2010) que nosso compromisso político com a emancipação social inclui necessariamente um deslocamento epistemológico do pensamento científico e do grande norte para um diálogo democrático que considere e reconheça, sem hierarquizar, diferentes conhecimentos como iguais - que busque justiça cognitiva, em outras palavras. Essa é uma condição para estabelecer a justiça social e a intensificação da democracia “consistentemente uma de nossas maiores preocupações no campo da educação como cidadãos da democracia brasileira" (SUSSEKIND, 2014b, p. 208).

É a virada epistemológica que "torna nossa grande questão mais que epistemológica, uma questão política" (Idem). Na perspectiva de uma possível epistemologia do sul (SANTOS, 2010), o diálogo é uma premissa; mais do que isso, a conversa é um paradigma do conhecimento. Aproxima-se do "movimento duplo que aponta para uma promessa e uma possibilidade" (p.13) proposto como "a promessa do irrealizável" na conversa de Spivak e Butler. Nesse contexto, a emancipação social é entendida como um conjunto interminável de batalhas processuais e contínuas, o que significa que o conhecimento social não preexiste aos sujeitos sendo uma negociação permanente e sugerido que numa compreensão solidária do mundo não há lugar para hierarquias fixas ou apriorísticas. Argumentamos sobre a necessidade de deslocar essa conversa com o Norte tomando distância segura e profundamente enraizada no Sul epistemológico (SANTOS, 2010; SUSSEKIND, 2014b, p. 209).

Abaixo do equador, pr'além das linhas abissais (SANTOS, 2010) do colonialismo, as marcas do heteropatriarcado, do racismo, dos fundamentalismos aprofunda abismos povoados de pessoas sem nação, dentro das nações. Nesse Estadonação que é como promessa irrealizável, para Butler, a "linha passa a existir politicamente o instante que alguém a atravessa ou tem seus direitos de passagem recusados" (p. 39).

Spivak e Butler discutem o tema da "fragilidade dos Direitos Humanos (DH)" (SANTOS, 2013, p. 9) com respeito de uma redeclaração dos DH (p. 48), uma refundação do Iluminismo (p. 99), como possibilidade - que leem em Arendt-, já em Santos (2013) a construção da Declaração dos DH, seus discursos e práticas, abrem 
áreas nubladas para o exercício e a defesa desses mesmos $\mathrm{DH}$, considerados conquistados. No entanto, é sob a defesa dos DH que residem violências e opressões, epistemicídios e genocídios, subalternizando e subjugando milhões de pessoas à situação de objetos dos discursos dos $\mathrm{DH}$ sem que sejam sujeitos dos mesmos direitos (SANTOS, 2013, p. 13). Os sujeitos dos DH são homens, brancos, europeus e de classe média (p. 37), e não Marielle ${ }^{l}$. Sobre essa des-humanidade, fala Butler, ainda dialogando com Arendt, que é "o que acontece no momento em que o nacionalismo assume um certo Estado-nação - o estado de direito é suspenso e as minorias são deportadas ou destituídas ou ainda aniquiladas" (p. 46) .

Nesse fluxo, Spivak chama atenção para importância da obra de Arendt ao ver o estado como uma estrutura abstrata e de múltiplas nacionalidades (p. 65, 66) desnaturalizando o hífen que os une. Por isso, o cantar do hino nacional americano em espanhol em Los Angeles e do hino brasileiro em Terena no Mato Grosso do Sul se diferencia, performaticamente, de cantar a Internacional Socialista, pois, em princípio, ele é intraduzível (p. 67). Mas, se para Butler isso é tão performático quanto um imigrante ilegal tirar uma carteira de motorista e, por isso, é um projeto epistêmico (p. 85), para Spivak, o segundo ato, é um problema, ou, apenas, um ato transgressor que faz uso da estrutura abstrata do estado, mas não enfrenta seu jugo pelo capitalismo, nacionalismo e outras estruturas de opressão.

Esses são aspectos que tornam ainda mais significativo o episódio do hino dos Estados Unidos cantado em espanhol. No entanto, o ato dos imigrantes ilegais implica uma transgressão que não se limita a uma questão linguística. Ocupar as ruas para protestar, exigir seus direitos e cantar o hino é um ato transgressivo tanto quanto, pois é uma ocupação que se assemelha a uma prática interpretativa: "O valor cultural do mesmo escrito ou da mesma rua varia segundo a utilização que se faz deles", afirma Certeau (1995, p. 248). Estamos diante do que Butler chama de contradição performativa. Essas pessoas, residentes ilegais de acordo com a lei, embora proibidas de se reunirem, fazem-no mesmo assim, expondo a rua como um local de livre congregação. Assim, o ato de cantar o hino, continua Butler, não apenas denota expressão de liberdade como também reencena a rua ao decretar a liberdade de congregação numa situação explicitamente proibida pela lei. Spivak, por sua vez, clama para que uma crítica persistente e permanentemente vigilante - como ela menciona em outros textos - esteja sempre atuando para que se questionem noções que, de outra forma, seriam consideradas naturalizadas e normatizadas (p. 12, 13).

\footnotetext{
${ }^{1}$ Marielle Franco, vereadora pelo PSOL, negra, homossexual e favelada, defensora e militante da causa dos Direitos Humanos, foi covardemente assassinada no Rio de Janeiro em abril de 2018. Ainda não há resultados das investigações no momento em que escrevo esse texto (dezembro de 2018).
} 
Pensando nas Ocupações estudantis de 2016, no Brasil, lembramos dos corpos e vozes dos estudantes fazendo outros usos das escolas, protestando e exigindo seu direito de existir nos currículos nacionais alimentando e desafiando a ideia de que a “educação é a arma mais poderosa que você pode usar para mudar o mundo ${ }^{2}$, aqui bem expressa na frase de Nelson Mandela e que vem sendo debatida como política e legislação embora, habite o campo da crença" (SUSSEKIND, 2014a). Como um dos possíveis desdobramentos desta ideia aparece a noção de currículo como projeto de nação assumindo "o papel de arma com um poder de educação destruição em massa" (p. 1514, 1526).

Este poder (de conservar ou revolucionar) devotado a um documento sugere não só seu entendimento escriturístico (CERTEAU, 1994, p. 270; SUSSEKIND, 2014a), mas subestima toda e qualquer interação social conforme vimos exaustivamente discutindo no campo desde sua fundação. Simplifica tudo, rejeita o conhecimento e reduz currículo à aprendizado, aprendizado a resultado, educação a currículo. Tenho entendido, desde então, que a questão dessa intencionalidade nos currículos é mais que um debate teórico permanente desdobrando-se numa questão política e epistemológica urgente que exige debates sobre cantos, ilações e projetos para o Estado-nação (defeituoso, p. 70) e sua condição e decisão política, e epistemológica, de nacionalizar os sem-nação e assumir sua multiplicidade de nações como os encarcerados, não documentados e todes que desfiam o Estado, e o estado em que estamos, ao cantar o hino nacional (p. 25, 26, 33, 68). Sejam os imigrantes refugiados na Europa e nos EUA, sejam os povos nativos aqui ou...

Diante das possibilidades irrealizadas, defende e chama atenção Spivak

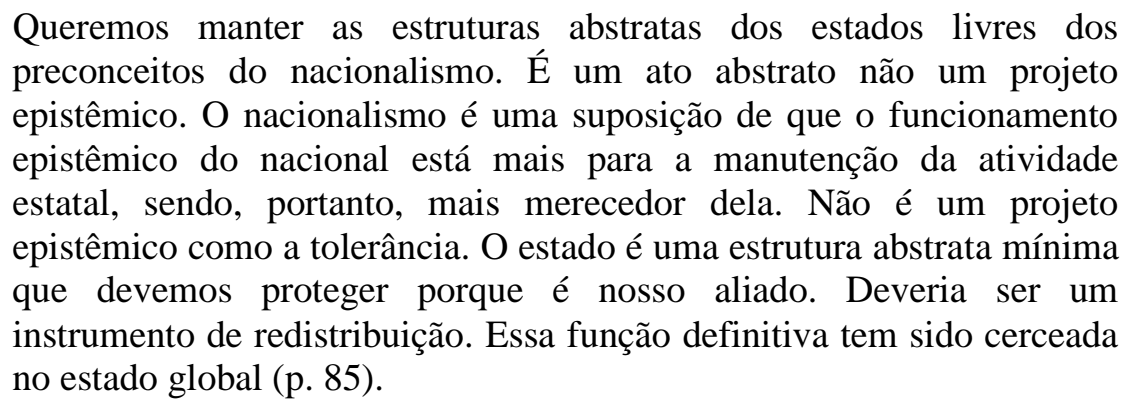

No inicio do século passado, John Franklin Bobbitt, acreditava que o currículo era uma maneira de preparar estudantes para seus futuros papéis na sociedade

\footnotetext{
${ }^{2}$ MANDELA, N. Lighting your way to a better future. Planetarium. University of the Witwatersrand, Johannesburg, South Africa. 16th July 2003.
} 
industrial, e argumento que ele influenciou o campo e os debates fora dele. Bobbitt argumentava que o ensino de disciplinas clássicas deveria ser substituído por disciplinas de ensino que correspondam às necessidades da sociedade industrial. Em 1918, ele escreveu O Currículo: um resumo do desenvolvimento relativo à teoria do currículo no qual defendeu que o currículo existia para listar quais resultados devem ser atingidos. Na mesma direção, o MEC (BRASIL, 2017, p.5) orienta que a BNCC é "o ponto ao qual se quer chegar em cada etapa da Educação Básica, enquanto os currículos traçam o caminho até lá".

De acordo com Paraskeva (2011), alimentando-se de e nutrindo esta crença, alguns estudiosos argumentaram que a educação seria uma ferramenta efetiva de mudança social, defendendo a ideia de que a educação poderia "modelar" e "melhorar" a sociedade e "forjar" cidadãos-trabalhadores (p. 53). Este argumento assumiu um papel de dominância, embora nunca uníssona, e edificou-se sobre os conflitos a respeito do papel da cultura e do primado da ciência, entre outros. Esses múltiplos entendimentos da relação entre educação e sociedade, não apenas conduziram os debates sobre currículo por muitos anos, mas como o autor demonstra claramente, a ideia do "currículo como arma" é uma ideia que relega todas as outras noções de currículo a um papel menos importante.

Apesar de todos os esforços para desenvolver currículos, métodos, objetivos, formas de avaliação (PARASKEVA, 2011, p. 69) e seus resultados equivocados (PINAR, 2008) foi preciso reformular o modo como a relação entre educação e sociedade era orientada por ideais demasiadamente audaciosos (PARASKEVA, 2011, p. 69) e como a educação foi tomada como uma "ferramenta simples" (idem) revelandose totalmente inadequada para responder ao que o industrialismo exigiu. Paraskeva explica que então o campo tornou-se altamente desenvolvido, não apenas por causa da importância que a relação sociedade-educação lhe atribui mas também por causa dos investimentos feitos pelo governo dos EUA para incrementar um novo território de conhecimento: o campo de "desenvolvimento curricular" orientado pelas ideias de eficiência, uniformização e treinamento profissional conforme exigia o avanço industrial contínuo e sua diversificação. Indo além, com Certeau (1994, p. 262), entendo a "cegueira técnica" que privilegia "autores, pedagogos, revolucionários numa palavra: produtores" motivada pela "eficácia da produção" que acaba por implicar "a inércia do consumo." (SUSSEKIND, 2014a, p. 1515).

Na mesma direção, o presidente do Inep ${ }^{3}$, Chico Soares apontou que a equidade é um fator importante, considerando que a $\mathrm{BCN}^{4}$ possibilitará a oportunidade para que "a sociedade brasileira defina sobre o que é ensinado nas escolas" e sugerindo que uma BCN teria o poder de promover a igualdade social. (SUSSEKIND, 2014a, p. 1518).

\footnotetext{
${ }^{3}$ Hoje membro do CNE.

${ }^{4}$ Hoje chamada BNCC, embora a troca de nome não tenha sido um caminho simples.
} 
Reafirmo (SUSSEKIND, 2014a; 2014b, entre outros), que, de acordo com Certeau (1994), as pessoas comuns, que ele chama de ordinárias, foram mal interpretadas como consumidores passivos de ideias. O uso (ou reuso) e a invenção (ou reinvenção) são festas multiformes (CERTEAU, 1994, p. 211) de abundância de oportunidades e astúcias que os cotidianos, em sua riqueza e transgressão oferecem para que as pessoas ordinárias, comuns, possam inverter, sub-verter, reverter e criar suas práticas e táticas de usos do estabelecido (SUSSEKIND, 2014a, p. 1518), máquina barulhenta, seja bélica (CERTEAU, 1994, p. 210, 272,273) ou uma política de currículos nacionais.

Os currículos constituem o instrumento mais significativo da intervenção do Estado no ensino, o que implica sua interferência, em última análise, na formação intelectual da clientela que frequenta os bancos escolares para a prática da cidadania, no sentido que interessa aos que se encontram representados no poder. (ABUD, K., In: BITTENCOURT, C., 1998, p. 28.)

Violências e opressões múltiplas se mostram presentes cartograficamente tanto na constituição das histórias, hinos, línguas e pertencimentos de pós-colonialidade quanto em cada sala de aula diante da aniquilação dos conhecimentos trazidos pelos estudantes e pelas experiências dos educadores e não servem senão para controlar e silenciar as práticas (inconformistas) invisibilizando suas outras lógicas (CERTEAU, 1994) e saberes (SANTOS, 2010) e violando sua condição de leitores dos currículos e usuários das línguas, das culturas, da cidadania e dos hinos nacionais. Leitores que inventam nos textos (e fronteiras, e hinos, e conhecimentos...) outros textos dando-lhes infinitos usos para finitas possibilidades, entendidos aqui no sentido dado por Certeau (1994, p. 268, 272).

"Por que estamos abordando literatura comparada e estados globais juntos?" (p. 15). Finalizando com a primeira pergunta feita por Butler a Spivak nessa conversa irruptiva, dissensuosa e de uma atualidade desafiadora para o campo do currículo, convidamos os leitores da Revista a conhecerem o livro e se deslocarem com as autoras nessa conversa complicada ${ }^{5}$ e implicada com a percepção inequívoca de Spivak de que

\footnotetext{
5"Pergunta - E por que os currículos seriam conversas complicadas?

Pinar - Porque as pessoas estão falando uma das outras. E porque os professores falam não só com seus estudantes, mas com seus próprios mentores, suas próprias experiências e com seus conteúdos, pois os conteúdos em si mesmos são conversas (...) essa conversa também é complicada por ser informada, é claro, por aquilo que acontece e aconteceu fora de sala, como nas famílias dos alunos. A conversa é complicada porque acontece entre todos na sociedade". (SUSSEKIND, 2014c)
} 
o "Iluminismo não é algo que acontece" (p. 99), assim recusando todas as formas de violência e opressão pois "O mundo sofre demais com essa oposição binária entre filosofia e prática, com a prática de expulsar a história como mitopoética para dentro da filosofia ou do pré-político. Tudo sofre (p. 100)".

\section{REFERÊNCIAS}

ABUD, Kátia. Currículos de História e políticas públicas: os programas de História do Brasil na escola secundária. In: BITTENCOURT, C. (Org.). O saber histórico na sala de aula. São Paulo: Contexto, 1998.

BRASIL. Base Nacional Comum Curricular. Quarta versão. Brasília: MEC/SEB, 2017. BOBBITT, John Franklin The Curriculum. Houghton Mifflin, Original de Harvard University, 1918. BUTLER, Judith. SPIVAK, Gayatri Chakravorty. Quem canta o Estado-nação? Língua política, pertencimento. Tradução e Prefacio: Vanderlei J. Zacchi, Sandra Goulart Almeida. Brasília: Editora Universidade de Brasília, 2018.

CERTEAU, Michel de. A invenção do cotidiano. Artes de fazer. Rio de Janeiro: Vozes, 1994.

MOURA, Fernanda Pereira de; SALLES, Diogo. da Costa. O Escola sem Partido e o ódio aos professores que formam crianças (des)viadas. Revista Periódicus, v.1, n. 9, 2018, p. 136-160 maio/out., 2018. Disponível em: < https://portalseer.ufba.br/index.php/revistaperiodicus/article/view/25742> Acesso em: 04 maio 2019.

OLIVEIRA, Inês Barbosa de; SUSSEKIND, Maria Luiza. Das teorias críticas às críticas das teorias: Um estudo indiciário sobre a conformação dos debates no campo curricular no Brasil. Revista Brasileira de Educação, v. 22, n. 71, 2017, p. 1-20, disponível em: $<$ http://www.scielo.br/scielo.php?pid=S141324782017000400212\&script=sci_abstract\&tlng=pt> Acesso em: 04 maio 2019

PARASKEVA, João Menelau. Conflicts in Curriculum Theory: Challenging Hegemonic Epistemologies. New York: Palgrave/MacMillan, 2011.

PINAR, William. A equivocada educação do publico nos Estados Unidos. In: GARCIA, R. L.; MOREIRA, A. F. B. (orgs). Currículo na Contemporaneidade: incertezas e desafios. São Paulo: Cortez, 2008.

SANTOS, Boaventura de Sousa. Para além do pensamento abissal. In: SANTOS, B. S.; MENESES, Maria P. (orgs). Epistemologias do Sul. São Paulo: Cortez, 2010.

SANTOS, Boaventura de Sousa. Se Deus fosse um activista dos direitos humanos. Coimbra: Ed. Almedina, 2013.

SUSSEKIND, Maria Luiza; FRELIN, Anneli; EDLING, Silvia; PRICE, Todd; LILJESTRAND, Johan; PINAR, William. Student teachers need more than evidence: arguments for the Place of Theory in the teacher education curriculum. In: ECCS - I

European Conference for Curriculum Studies Future Directions: Uncertainty and Possibility. Braga: Universidade do Minho. v. 2., 2013, p. 1-10.

SUSSEKIND, Maria Luiza. As (im)possibilidades de uma Base Comum Nacional. Revista E-Curriculum, v. 12, n. 03, p.1512 - 1529, out./dez. 2014a.

Taking Advantage of the Paradigmatic Crisis: Brazilian Everyday Life Studies 
as a new epistemological approach to the understanding of teachers' work. Citizenship, Social and Economics Education, v.13, n 3, p.199-210 2014b.Disponível em: < https://doi.org/10.2304/csee.2014.13.3.199> Acesso em: 04/maio/2019.

Quem é William F. Pinar. Petrópolis: de Petrus Et Alli, 2014c.

214, 2013.

Entrevista com William F. Pinar. Revista Teias (UERJ. Online), v. 14, p. 206-

EDITORA E GRÁFICA DA FURG

CAMPUS CARREIROS

CEP 96203900

editora@furg.br 